\title{
Synthesis and structure of $\mathrm{BiFeO}_{3}: \mathrm{RE}\left(\mathrm{RE}=\mathrm{Gd}^{3+}, \mathrm{Dy}^{3+}, \mathrm{Nd}^{3+}\right)$ ceramics
}

\author{
J. Dzik ${ }^{1, a}$, M. Płońska ${ }^{1}$, T. Pikula ${ }^{2}$, M. Rerak ${ }^{1}$ \\ ${ }^{1}$ University of Silesia in Katowice, Faculty of Computer Science and Material Science, Institute of Technology and Mechatronics \\ 12, Żytnia St., 41-200, Sosnowiec, Poland \\ 2 Lublin University of Technology, Institute of Electronics and Information Technology, 38A Nadbystrzycka Str., 20-618 Lublin, Poland
}

\begin{abstract}
In the present work the influence of rare earth elements concentration $(0-10 \mathrm{at}-\%)$ on $\mathrm{BiFeO}_{3}: \mathrm{RE}\left(\mathrm{RE}=\mathrm{Gd}^{3+}\right.$, $\mathrm{Dy}^{3+}, \mathrm{Nd}^{3+}$ ) ceramics were studied. All ceramic powders were synthesized by conventional ceramic method using high purity raw materials $(>99,9 \%)$, and subsequently sintered by free sintering and cold pressing method. To analyze the powders and ceramics more the XRD, EDS, SEM, and DTA were performed.
\end{abstract}

\section{Introduction}

Multiferroic materials are the subject of intensive research during recent years, due to their interesting physical properties [1], as well as the great technological potential of the materials for microelectronics and spintronics [2,3]. In these materials in which ferro/antiferromagnetic and ferroelectric properties occur simultaneously. Bismuth ferrite and its materials are attracting great attention owing to both great technological potential and the interesting physics behind their functional properties [4]. $\mathrm{BiFeO}_{3}$ ceramic is an interesting candidate due to its high ferroelectric curie temperature $\left(\mathrm{T}_{\mathrm{C}}=850^{\circ} \mathrm{C}\right)$ and antiferromagnetism below Neel temperature $\left(\mathrm{T}_{\mathrm{N}}=370^{\circ} \mathrm{C}\right)[5,6]$. These characteristics are unrepeatable, taking into account that most magnetic ferroelectrics possess coexisting spin and dipole order only well below room temperature. At room temperature, $\mathrm{BiFeO}_{3}$ single crystal has distorted rhombohedral (R) structure with lattice parameter of $\left(\mathrm{a}_{\mathrm{r}}=3.96 \AA\right.$ and $\mathrm{a}_{\mathrm{r}}=89.41 \AA$ ) [7]. The magnetic ordering is G-type with a weak canting moment with a $62 \mathrm{~nm}$ spin cycloid [8]. When discussing the properties of bismuth irons, it should be noted that information on the $\mathrm{BiFeO}_{3}$ formations and temperature stability limits remains ambiguous. Despite the fact that bismuth ferrite is characterized by very good physical properties, attempts are made to improve the ferroelectric and ferromagnetic properties. One possible strategy for obtaining improved properties in $\mathrm{BiFeO} 3$ is partial ionic substitution. Additionally, the pure, single-phase bismuth ferrite is typically very difficult to obtain via solid-state reaction of $\mathrm{Bi}_{2} \mathrm{O}_{3}$ and $\mathrm{Fe}_{2} \mathrm{O}_{3}$ [9]. During its preparation additional (impurity) phases such as $\mathrm{Bi}_{2} \mathrm{Fe}_{4} \mathrm{O}_{9}, \mathrm{Bi}_{36} \mathrm{Fe}_{24} \mathrm{O}_{57}$ or $\mathrm{Bi}_{25} \mathrm{FeO}_{39}$ appear very often $[10,11]$. Lomanova et al [12]

\footnotetext{
a jolanta.dzik@us.edu.pl
}

reported the possibility of $\mathrm{Bi}_{2} \mathrm{Fe}_{4} \mathrm{O}_{9}$ and $\mathrm{Bi}_{25} \mathrm{FeO}_{39}$ formation during $\mathrm{BiFeO}_{3}$ synthesis and it was shown to be dependent upon the quality of the initial reagents [19]. They argue that not enough pure precursors can result in the formation of the above-mentioned phases and to their stable existence as impurities during $\mathrm{BiFeO}_{3}$ formation. Other authors postulate that it is difficult to synthesize the single-phase $\mathrm{BiFeO}_{3}$ because $\mathrm{Bi}_{2} \mathrm{Fe}_{4} \mathrm{O}_{9}$ and $\mathrm{Bi}_{25} \mathrm{FeO}_{39}$ are thermodynamically more stable than $\mathrm{BiFeO}_{3}$. It has been observed that the partial substitution of $\mathrm{Bi}$ atoms by elements like $\mathrm{Eu}, \mathrm{La}, \mathrm{Nd}, \mathrm{Sm}, \mathrm{Tb}[13,14,15]$ allows to eliminate the impurity phases. The short review of the results of experimental investigations of bismuth ferrite shows the necessity of performing more comprehensive and deeper research. Special attention should be paid to rare-earth substituted compounds, whose properties remain poorly known what can be stated after reading the available literature. Aim of this study was to synthesize and fabricate $\mathrm{Bi}_{1-\mathrm{x}} \mathrm{A}_{\mathrm{x}} \mathrm{FeO}_{3}((\mathrm{~A}=\mathrm{Nd}, \mathrm{Gd}$, Dy, for $\mathrm{x}=0.03$, $0.05,0.07,0.1)$ ceramics by solid state reaction. By means of simultaneous thermal analysis (TG / DTG, DTA) and X-ray diffraction analysis the process of synthesis of $\mathrm{Bi}_{1-\mathrm{x}} \mathrm{A}_{\mathrm{x}} \mathrm{FeO}_{3}$ ceramics has been studied.

\section{Experimental}

\subsection{The technology of the PFN material}

The preparation and synthesis process of undoped and $\mathrm{Gd}^{3+}, \mathrm{Dy}^{3+}$ and $\mathrm{Nd}^{3+}$ co-doped $\mathrm{BiFeO}_{3}$ powders was performed through the solid state reaction, by the conventional ceramic method. Stoichiometric amounts of high purity oxdides powders, $\mathrm{Bi}_{2} \mathrm{O}_{3}$ (Sigma - Aldrich, 
99,9\%), $\mathrm{Fe}_{2} \mathrm{O}_{3}$ (Sigma - Aldrich, 99,9\%), $\mathrm{Nd}_{2} \mathrm{O}_{3}$ (Sigma - Aldrich, 99,9\%), $\mathrm{Gd}_{2} \mathrm{O}_{3}$ (Sigma - Aldrich, 99,9\%), $\mathrm{Dy}_{2} \mathrm{O}_{3}$ (Sigma - Aldrich, 99,9\%) were weighed according to the nominal composition of $\mathrm{Bi}_{1-\mathrm{x}} \mathrm{A}_{\mathrm{x}} \mathrm{FeO}_{3}$. The appropriate quantities of reagents were weighed according to the formula (1):

$$
\left(\frac{1-x}{2}\right) \mathrm{Bi}_{2} \mathrm{O}_{3}+\left(\frac{x}{2}\right) \mathrm{A}_{2} \mathrm{O}_{3}+\left(\frac{1}{2}\right) \mathrm{Fe}_{2} \mathrm{O}_{3} \rightarrow \mathrm{Bi}_{1-x} \mathrm{~A}_{x} \mathrm{FeO}_{3}
$$

The high purity $(99.9 \%)$ oxide powders were ground homogeneously in the mortar at room temperature for 1 h. Next, these mixtures were subjected to grind in a ball mill for $24 \mathrm{~h}$ using YTZ balls as grinding media in ethanol solution. The dried mixture of powders was compacted into pellets of $20 \mathrm{~mm}$ in diameter by pressing under pressure of $\mathrm{p}=60 \mathrm{MPa}$ in a stainless - steel die. The synthesis was carried out at $T=800^{\circ} \mathrm{C}$ in corundum crucible with air atmosphere for $3 \mathrm{~h}$. Calcined material were remilled for $24 \mathrm{~h}$ to reduce the particle size, and then cold pressed into pellets $(\mathrm{d}=10 \mathrm{~mm}, \mathrm{p}=30 \mathrm{MPa})$. Then the material was sintered in air at the temperature of $T=860^{\circ} \mathrm{C}$ for $3 \mathrm{~h}$. The flowchart of the complete fabrication process is shown in Fig. 1.

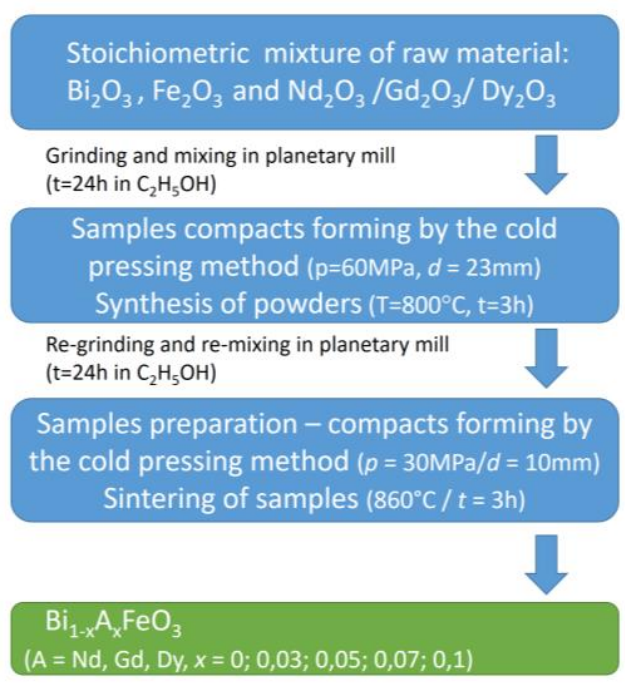

Fig. 1 The flowchart of fabrication process of $\mathrm{Bi}_{1-x} \mathrm{~A}_{x} \mathrm{FeO}$ ceramics.

\subsection{Characterization}

Microstructure and chemical composition of the final ceramics were investigated by scanning electron microscope (SEM) JSM - 7100F equipped with an energy dispersive spectrometer (EDS) NORAN Vantage. The microscope was operating at $15 \mathrm{kV}$ acceleration voltage. Structure of the samples was investigated using PANAlytical X-Pert Pro difractometer with $\mathrm{Cu}$ lamp $(\lambda=$ $0.154 \mathrm{~nm})$. X'Pert HighScore Plus computer program equipped with the ICDD PDF2 data base was used to phase analysis and Rietveld refinement of the structure. The densities of the sintered pellets were measured by Archimedes' principles. Parameters of the thermal treatment were determined by simultaneous thermal analysis (DTA/TG/DTG). Simultaneous measurements were executed by heating the dried powders in air at $10^{\circ} \mathrm{C} / \mathrm{min}$. The test specimens were prepared in powder form, the reference material was aluminum oxide $\mathrm{Al}_{2} \mathrm{O}_{3}$. The simultaneous thermal analysis method enables to determine the optimum synthesis temperature.

\section{Results and discussion}

\subsection{Density}

Fig. 2 shows the density of obtained ceramic samples $\mathrm{Bi}_{1-\mathrm{x}} \mathrm{A}_{\mathrm{x}} \mathrm{FeO}_{3}$. Density of the samples is closely related to the type of dopant and its content in the material. For the dopant neodymium and dysprosium it can be concluded that with increase of the dopant content in the studied ceramics its density rises too. Vice versa in the case of dopant gadolinium: with increase of the dopant content the density of the ceramic decreases.

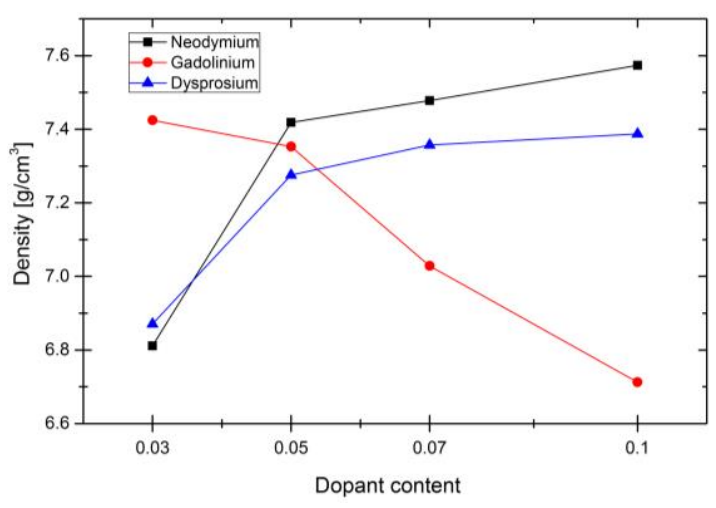

Fig. 2 Effect of dopant content on the density of ceramic samples.

\subsection{Simultaneous thermal analysis}

Simultaneous thermal analysis, in which thermal analysis and mass change effects are measured concurrently on the same sample was used to investigate synthesis effects in the stoichiometric mixture of powders. A DTA curve obtained for the stoichiometric mixture of $\mathrm{Bi}_{2} \mathrm{O}_{3}, \mathrm{Fe}_{2} \mathrm{O}_{3}$ and $\mathrm{Nd}_{2} \mathrm{O}_{3}$ powders for $\mathrm{Bi}_{0.9} \mathrm{Nd}_{0.1} \mathrm{FeO}_{3}$ is shown in Fig. 3 . One can see there are at least two temperature ranges showing rates of the mass loss, namely $\Delta T_{1} \approx(290-400)^{\circ} \mathrm{C}$ and $\Delta T_{2} \approx(580-800)^{\circ} \mathrm{C}$. The mentioned mass loss is accompanied by a thermal effect in the form of exothermic peaks in the DTA curve. The DTG curve shows the rate of mass loss as a function of temperature. With the DTG curve it is possible to determine the start and the end of each change-weight temperature region, in other words, the range of the reaction and evaporation of absorbed $\mathrm{H}_{2} \mathrm{O}$ and $\mathrm{CO}_{2}$, as well as slight evaporation of the starting oxides $-\mathrm{Bi}_{2} \mathrm{O}_{3}$ (in this case), and the reading of the TG curve of the mass change value. Thermogravimetric (TG) plots show that mass loss 
reaches a value of $\Delta \mathrm{m}=-1 \%$ at $\mathrm{T}=800^{\circ} \mathrm{C}$. The observed weight loss one can ascribe with evaporation of products and/or by-products of chemical reactions as well as evaporation of $\mathrm{Bi}_{2} \mathrm{O}_{3}$ oxide. At temperature $\mathrm{T}>800^{\circ} \mathrm{C}$ no mass change effects occurred. From the practical point of view DTA, TG and DTG curves help to choose the appropriate rate of the thermal treatment of the studied material. The temperature of synthesis was chosen as $\mathrm{T}=800^{\circ} \mathrm{C}$.

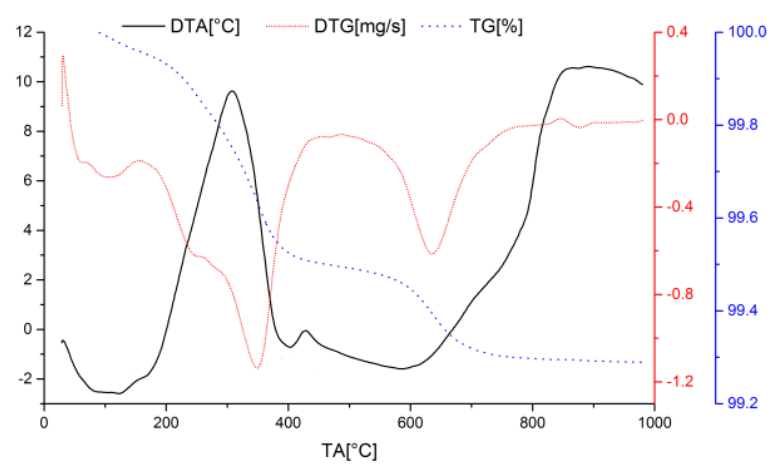

Fig. 3 Differential thermal analysis (DTA) curves for stoichiometric mixtures of oxides used for synthesis of $\mathrm{Bi}_{0.9} \mathrm{Nd}_{0.1} \mathrm{FeO}_{3}$.

\subsection{X-ray diffraction analysis}

The results of XRD measurements are presented in Fig. 5. Diffraction lines corresponding to impurity phases $\left(\mathrm{Bi}_{2} \mathrm{Fe}_{4} \mathrm{O}_{9}\right)$ were marked by symbols whereas all other lines belong to the main phase, i.e. $\mathrm{Bi}_{0,9} \mathrm{~A}_{0,1} \mathrm{FeO}_{3}$ solid solution with a suitable dopant marked on the image. Analysis of the X-ray diffraction patterns of the ceramic powders was carried out using a computer program PowderCell [16]. Refinement of the structural parameters of $\mathrm{Bi}_{0.9} \mathrm{~A}_{0.1} \mathrm{FeO}_{3}$ solid solutions was performed with the Rietveld method e.g. [17,18]. The angular position of diffraction lines agree well with positions for rhombohedral $\mathrm{BiFeO}_{3}$ phase given in ICDD 01-082-1254 card. A small content of $\mathrm{Bi}_{2} \mathrm{Fe}_{4} \mathrm{O}_{9}$ was also noticed (99100-8872).

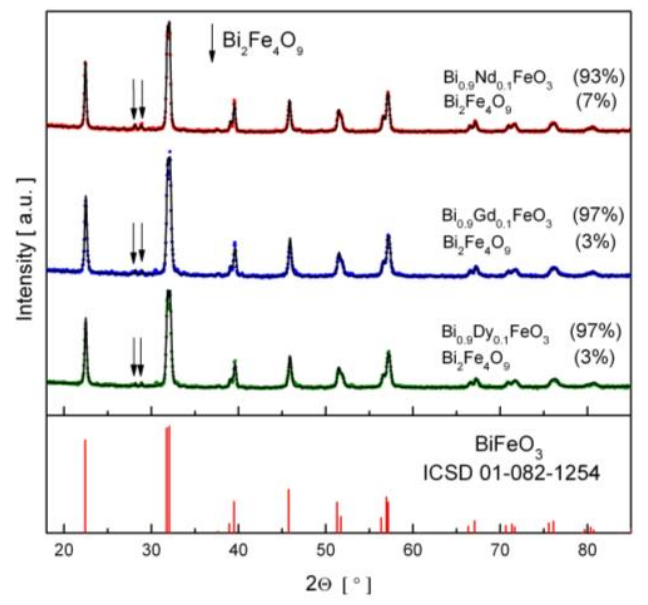

Fig. $4 \mathrm{X}$-ray diffraction patterns of $\mathrm{Bi}_{0.9{ }_{0.1} \mathrm{~A}_{0.1} \mathrm{FeO}}$ solid solutions.

On the basis of analysis of diffractograms it was concluded that the structure of the obtained solid materials was rhombohedral (R3c space group). Also the weight fraction of phases from diffractograms was estimated. Diffraction lines coming from impurity phases are rather small. The occurrence of weak lines for $2 \theta=$ $27^{\circ}$ isn't connected with the $\mathrm{BiFeO}_{3}$-type structure and rather caused by the presence of a vestigial quantity of $\mathrm{Bi}_{2} \mathrm{Fe}_{4} \mathrm{O}_{9}$. For the content of neodymium $\mathrm{x}=0.1$ the concentration of the main phase, i.e. $\mathrm{Bi}_{0.9} \mathrm{Nd}_{0.1} \mathrm{FeO}_{3}$, is about 93 wt.\%. The rest are impurity phases, namely $\mathrm{Bi}_{2} \mathrm{Fe}_{4} \mathrm{O}_{9}$ in amount 7 wt.\%. For $\mathrm{x}=0.1$ of dysprosium the concentration of the main phase, i.e. $\mathrm{Bi}_{0.9} \mathrm{Dy}_{0.1} \mathrm{FeO}_{3}$, is about 97 wt.\%, whereas the impurity phases, namely $\mathrm{Bi}_{2} \mathrm{Fe}_{4} \mathrm{O}_{9}$ in amount 3 wt.\%. The weight fraction of phases from diffractograms for the $\mathrm{x}=0.1$ gadolinium are the same like a $\mathrm{Bi}_{0.9} \mathrm{Dy}_{0.1} \mathrm{FeO}_{3}$ (as shown in Fig. ). In another author's work on the influence of rare earth ions on $\mathrm{BiFeO}_{3}$, it is shown that a higher neodymium dopant concentration results in a single phase material [19]. Results of calculations of elementary cell parameters as well as agreement indices are given in Table 1.

Table 1 Structural parameters of $\mathrm{Bi}_{0.9} \mathrm{R}_{0.1} \mathrm{FeO}_{3}(\mathrm{R}=\mathrm{Nd}$, $G d, D y)$ derived from Rietveld refinement of XRD

patterns.

\begin{tabular}{|c|c|c|c|c|}
\hline & $\mathrm{BiFeO}_{3}+\mathrm{Nd}$ & $\mathrm{BiFeO}_{3}+\mathrm{Gd}$ & $\mathrm{BiFeO}_{3}+\mathrm{Dy}$ \\
\hline \multicolumn{2}{|c|}{ Cryst. system } & Rhomboh. & Rhomboh. & Rhomboh. \\
\hline \multicolumn{2}{|c|}{ Space group } & R3c & R3c & R3c \\
\hline \multirow{2}{*}{$\begin{array}{c}\text { Lattice } \\
\text { param. } \mathrm{nm}\end{array}$} & $\mathbf{a}=\mathbf{b}$ & $0.55716(2)$ & $0.55672(3)$ & $0.55645(3)$ \\
\hline & c & $1.38047(3)$ & $1.38127(5)$ & $1.38174(4)$ \\
\hline \multicolumn{2}{|c|}{ Volume $\left[\mathrm{nm}^{3}\right]$} & 0.37112 & 0.37074 & 0.37052 \\
\hline \multirow{3}{*}{$\begin{array}{l}\text { Agreement } \\
\text { indices }\end{array}$} & $\mathbf{R}_{\text {exp }}$ & 3.9 & 3.5 & 3.7 \\
\hline & $\mathbf{R}_{\text {prof }}$ & 4.1 & 4.8 & 4.6 \\
\hline & $\chi^{2}$ & 1.8 & 3.0 & 2.5 \\
\hline
\end{tabular}

The determined lattice parameters from the number of atomic (dopants) are presented in Fig. . The linear drop in the values of a lattice constant may be observed while $c$ parameter increases with the increase of the atomic number.

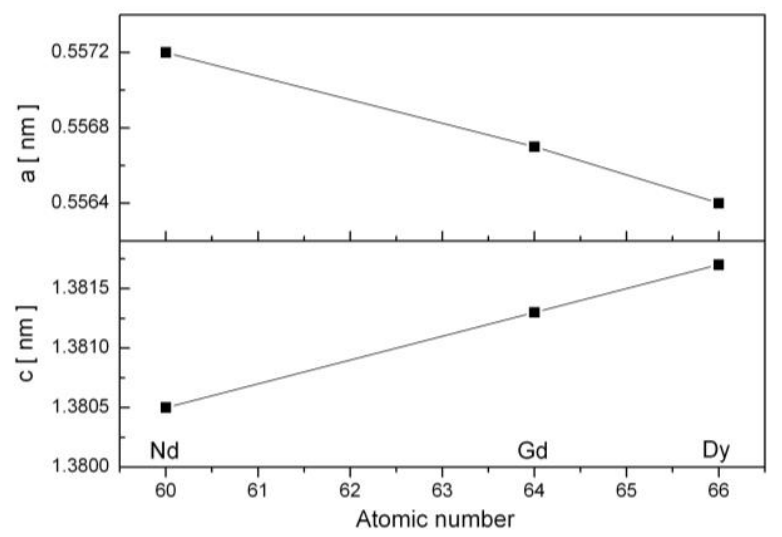


Fig. 5 Lattice constants of $\mathrm{Bi}_{0.9} \mathrm{Nd}_{0.1} \mathrm{FeO}_{3}$ solid solutions with rhombohedral structure.

\subsection{Microstructural and EDS tests}

Using scanning electron microscopy analysis microstructure was performed and the chemical compositions of obtained materials were determined. SEM pictures of $\mathrm{Bi}_{0.97} \mathrm{~A}_{0.03} \mathrm{FeO}_{3}$ ceramics obtained by pressureless sintering from stoichiometric mixtures of oxides are shown in Fig.6. Analyzing the SEM image it can be noted, that addition of the individual dopants did not affect the packing of the beans. The shape of the grains changed.
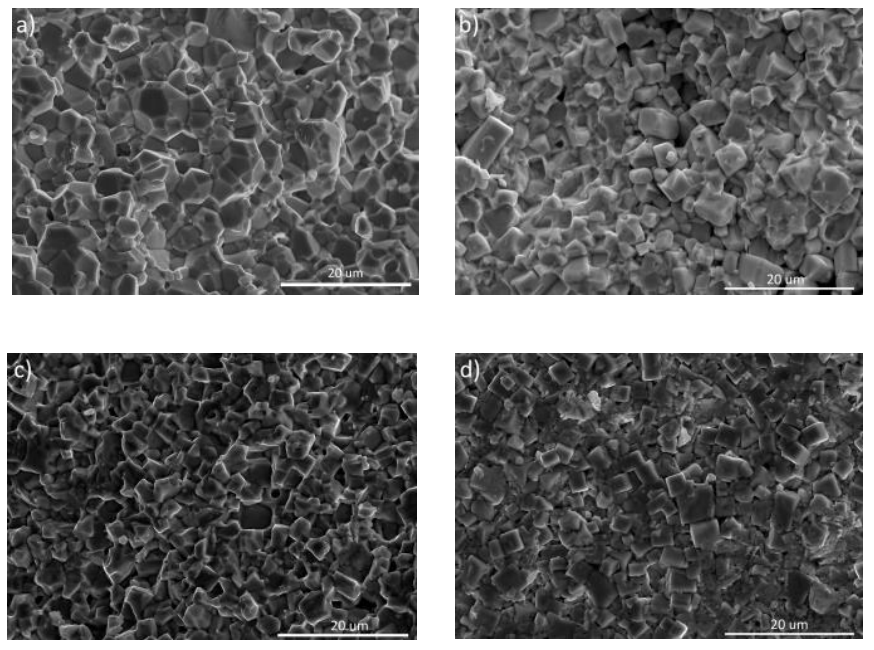

Fig. 6 SEM photographs of fracture for a) $\mathrm{BiFeO}_{3}$; b) $\left.\mathrm{Bi}_{0,97} \mathrm{Nd}_{0,03} \mathrm{FeO}, ; \mathrm{c}\right) \mathrm{Bi}_{0,97} \mathrm{Gd}_{0,03} \mathrm{FeO}_{3}$; d) $\mathrm{Bi}_{0,97} \mathrm{Dy}_{0,03} \mathrm{FeO}$ ceramics.

The distribution of all elements was investigated with Energy Dispersion X-ray spectrometer (EDS) and carried out for randomly selected areas. Obtained results are very close to the calculated stoichiometric ratio for each prepared material. The small deviations from the theoretical composition have occurred but they do not exceed a value of $2.7 \%$, what is consistent with the resolution of the utilized method of investigation.

Tab. 2 Theoretical and experimental content of element (calculation for simple oxide) for $\mathrm{Bi}_{0.9} \mathrm{~A}_{0.1} \mathrm{FeO} \mathrm{O}_{3}$ ceramic.

\begin{tabular}{|c|c|c|c|c|}
\hline & & $\mathrm{BiNdFeO}$ & $\mathrm{BiGdFeO}$ & $\mathrm{BiDyFeO}$ \\
\hline \multirow{2}{*}{$\begin{array}{c}\text { Oxide content } \\
\text { by EDS } \\
\text { measurement [\%] }\end{array}$} & $\mathrm{Bi}_{2} \mathrm{O}_{3}$ & 68,44 & 68,154 & 67,972 \\
\cline { 2 - 5 } & $\mathrm{A}_{2} \mathrm{O}_{3}$ & 5,491 & 5,891 & 6,143 \\
\cline { 2 - 5 } $\begin{array}{c}\mathrm{Fe}_{2} \mathrm{O}_{3} \\
\text { Theoretical } \\
\text { content of oxides } \\
{[\%]}\end{array}$ & $\mathrm{Bi}_{2} \mathrm{O}_{3}$ & 66,064 & 25,953 & 25,884 \\
\cline { 2 - 5 } & $\mathrm{A}_{2} \mathrm{O}_{3}$ & 5,5 & 67,9 & 67,95 \\
\cline { 2 - 5 } & $\mathrm{Fe}_{2} \mathrm{O}_{3}$ & 26,48 & 26,05 & 6,21 \\
\hline \multirow{2}{*}{$\begin{array}{c}\text { Content error } \\
{[\%]}\end{array}$} & $\mathrm{Bi}_{2} \mathrm{O}_{3}$ & 0,614 & 0,373 & 25,84 \\
\cline { 2 - 5 } & $\mathrm{A}_{2} \mathrm{O}_{3}$ & 0,164 & 2,699 & 0,032 \\
\cline { 2 - 5 } & $\mathrm{Fe}_{2} \mathrm{O}_{3}$ & 1,596 & 0,374 & 0,17 \\
\hline
\end{tabular}

\section{Conclusion}

By means of the mixed oxide method followed by pressureless sintering $\mathrm{Bi}_{1-\mathrm{x}} \mathrm{A}_{\mathrm{x}} \mathrm{FeO}_{3}(\mathrm{~A}=\mathrm{Nd}, \mathrm{Gd}$, Dy, for $x$ $=0,0.03,0.05,0.07,0,1)$ ceramics was successfully fabricated from stoichiometric mixture of $\mathrm{Bi}_{2} \mathrm{O}_{3}, \mathrm{Fe}_{2} \mathrm{O}_{3}$ and $\mathrm{Nd}_{2} \mathrm{O}_{3} / \mathrm{Gd}_{2} \mathrm{O}_{3} / \mathrm{Dy}_{2} \mathrm{O}_{3}$ powders, via the solid state reaction route. The thermal analysis method enables to determine the optimum synthesis temperature. The temperature of synthesis was chosen as $\mathrm{T}=800^{\circ} \mathrm{C}$. The density of ceramic samples depends on the type and content of dopant. Increase of the content of neodymium and dysprosium increases the density of the obtained materials, but with increasing of gadolinium dopant the density of the ceramics decreases. Analyzing the SEM image it can be noted, that addition of the individual dopants did not affect the packing of the beans. The shape of the grains changed. It was found that $\mathrm{Bi}_{1-\mathrm{x}} \mathrm{A}_{\mathrm{x}} \mathrm{FeO}_{3}$ ceramics exhibited rhombohedral symmetry with R3c (36) space group.

\section{References}

[1] M. Fiebig, Revival of the magnetoelectric effect, J. Phys. D - Appl. Phys. 38, R123 (2005)

[2] V.A. Khomchenko, V.V. Shvartsman, P. Borisov, W. Kleemann, D.A. Kiselev, I.K. Bdikin, J.M. Vieira, A.L. Kholkin, Effect of Gd substitution on the crystal structure and multiferroic properties of $\mathrm{BiFeO}_{3}$, Acta Materialia 57, 5137-5145 (2009)

[3] N. Hur, S. Park, P.A. Sharma, J.S. Ahn, S. Guha, S.-W. Cheong, Nature 429, 392-395 (2004)

[4] V.Koval, I.Skorvanek, M.Reece, L.Mitoseriu, H.Yanc, Effect of dysprosium substitution on crystal structure and physical properties of multiferroic $\mathrm{BiFeO}_{3}$ ceramics, Journal of the European Ceramic Society Volume 34, Issue 3 (2014)

[5] D.G. Chena, X.G. Tangb, Q.X. Liuc, X.F. Chengd and Y. Zoue, The Nd-doping effect on dielectric abnormity of $\mathrm{BiFeO}_{3}$ ceramics below the Néel temperature, Materials Science Forum Vol. 687, pp 439-446 (2011)

[6] Kazhugasalamoorthy S., Jegatheesan P., Mohandoss R., Giridharan N.V., Karthikeyan B., Investigations on the properties of pure and rare earth modified bismuth ferrite, Ceramics, Journal of Alloys and Compounds 493, 569-572 (2010)

[7] Pradhan S.K., Das J., Rout P.P., Das S.K., Mishra D.K., Sahu D.R., Pradhan A.K., Srinivasu V.V., Nayak B.B., Verma S., Roul B.K., Defect driven multiferroicityin $\mathrm{Gd}$ doped $\mathrm{BiFeO} 3$ at room temperaturę, Journal of Magnetism and Magnetic Materials 322 , 3614-3622 (2010)

[8] Sosnowska I., Peterlin-Neumaier T., and Steichele E., Spiral magnetic- ordering in bismuth ferrite, J. Phys. C: Solid State Phys. 15, pp. 4835-4846. (1982) 
[9] A. Gajovic, S. Sturm, B. J. War, A. Santic, J. K. Zagar, M. Ceh, The Synthesis of Pure-Phase Bismuth Ferrite in the $\mathrm{Bi}-\mathrm{Fe}-\mathrm{O}$ System Under Hydrothermal Conditions without a Mineralizer, J. Am. Ceram. Soc.,93[10] 3173-3179 (2010)

[10] M.S. Bernardo, T. Jardiel, M. Peiteado, A.C. Caballero, M. Villegas, Reaction pathways in the solid state synthesis of multiferroic $\mathrm{BiFeO}_{3}$, Journal of the European Ceramic society, 31 (2011) 3047-3053

[11] Khesro A., Boston R., Sterianou I., Sinclair D.C., and Reaney I.M., Phase transitions, domain structure, and pseudosymmetry in La- and Tidoped $\mathrm{BiFeO}_{3}$, Journal Of Applied Physics 119, 054101 (2016)

[12] N. A. Lomanova, V. V. Gusarov, Influence of synthesis temperature on $\mathrm{BiFeO}_{3}$ nanoparticles formation, Nanosystems: Physics, Chemistry, Mathematics, 4 (5), P. 696-705

(2013)

[13] S.T. Zhang, Y. Zhang, M.H. Lu, C.L. Du, Y.F. Chen, Z.G. Liu, Y.Y. Zhu, N.B. Ming, Substitution-induced phase transition and enhanced multiferroic properties of $\mathrm{Bi}_{1-\mathrm{x}} \mathrm{La}_{\mathrm{x}} \mathrm{FeO}_{3}$ ceramics, Appl. Phys. Lett. 88 (2006)

[14] V.F. Freitas, H.L.C. Grande, S.N. de Medeiros, I.A. Santos, L.F. Cotica, A.A. Coelho, Structural, microstructural and magnetic investigations in high-energy ball milled $\mathrm{BiFeO}_{3}$ and $\mathrm{Bi}_{0.95} \mathrm{Eu}_{0.05} \mathrm{FeO}_{3}$ powders, J. Alloy Comp. 461 (2008)

[15] Y.-Jie Zhang, H.-Guo Zhang, J.-Hua Yin, H.-Wei Zhang, J.-Ian Chen, W.-Quan Wang, G.-Heng Wu, Structural and magnetic properties in $\mathrm{Bi}_{1-\mathrm{x}} \mathrm{R}_{\mathrm{x}} \mathrm{FeO}_{3}$ ( $\mathrm{x}=0-1, \mathrm{R}=\mathrm{La}, \mathrm{Nd}, \mathrm{Sm}, \mathrm{Eu}$ and $\mathrm{Tb}$ ) polycrystalline ceramics, J. Magn. Magn. Mater. 322 (2010)

[16] W. Kraus, G. Nolze, Powder cell - a program for the representation and manipulation of crystal structures and calculation of the resulting X-ray powder patterns, Journal of Applied Crystallography, 29, 301-303 (1996)

[17] H.M. Rietveld, The Rietveld method - a historical perspective, Austr. J. Phys., 113-116 (1988)

[18] Z. Bojarski, E. Łagiewka, Rentgenowska analiza strukturalna, Wydawnictwo Uniwersytetu Sląskiego, Katowice (1995)

[19] T. Pikula, J. Dzik, A. Lisinska-Czekaj, D. Czekaj, E. Jartych, Structure and hyperfine interactions in $\mathrm{Bi}_{1-\mathrm{x}} \mathrm{Nd}_{\mathrm{x}} \mathrm{FeO}_{3}$ solid solutions prepared by solidstate sintering, Journal of Alloys and Compounds 606, 1-6 (2014) 